\title{
Механизмы и инструменты гуманитарного и культурного взаимодействия России с государствами на постсоветском пространстве
}

\author{
Конышева Ю.С. \\ Среднерусский институт управления - филиал РАНХиГС, \\ Россия, 302028, г. Орёл, Бульвар Победы, д. 5А \\ E-mail: yuli-konysheva@yandex.ru
}

\begin{abstract}
Аннотация. Целью статьи является рассмотрение влияния государственных и региональных механизмов на развитие международных отношений Российской Федерации на постсоветском пространстве. Автор обобщает научные подходы к пониманию и применению в практической среде государственных механизмов в международной деятельности. Автор также определяет их значение для положения современной России в постсоветском мире. Обобщается, что стратегическая проблема концептуального обеспечения практического применения механизмов и решений на международном уровне заключается в недостаточной системности и координации в деятельности государственных ведомств и их партнерства с неправительственными аналитическими и экспертными институтами постсоветского пространства. Указывается на отсутствие устойчивого интереса к внедрению в российской внешней политике технологий и методов публичной дипломатии, зарекомендовавших себя в зарубежной практике международного сотрудничества. В качестве приоритетов развития и распространения положительных настроений на постсоветском пространстве называются развитие сотрудничества с неправительственными организациями и институтами гражданского общества стран СНГ, продвижение сетевых коммуникаций взаимодействия в обеспечении международного гуманитарного обмена.
\end{abstract}

Ключевые слова: мировое пространство, язык, международная деятельность, соотечественники, сотрудничество, государство, напряженность, система образования, экономика, наука.

Для цитирования: Конышева Ю.С. 2021. Механизмы и инструменты гуманитарного и культурного взаимодействия России с государствами на постсоветском пространстве. Via in tempore. История. Политология. 48 (4): 942-952. DOI: 10.52575/2687-0967-2021-48-4-942-952.

\section{Mechanisms and tools of humanitarian and cultural cooperation between Russia and the states in the post-Soviet space}

\author{
Yulia S. Konysheva \\ Central Russian Institute of Management - branch of RANEPA \\ Russia 302028, Orel, Victory Boulevard 5A, \\ E-mail: yuli-konysheva@yandex.ru
}

\begin{abstract}
The purpose of the article is to consider the influence of state and regional mechanisms on the development of international relations of the Russian Federation in the post-Soviet space. The author summarizes scientific approaches to understanding and application in the practical environment of state mechanisms in international activities. The author also determines their significance for the situation of modern Russia in the post-Soviet world. It is summarized that the strategic problem of conceptualizing the practical application of mechanisms and solutions at the international level is the lack of system and coordination in the activities of state departments, and their partnership with non-governmental analytical and expert institutions of the post-Soviet space. It
\end{abstract}


is indicated that there is no sustained interest in the introduction of technologies and methods of public diplomacy in Russian foreign policy, which have proven themselves in foreign practice of international cooperation. The development of cooperation with non-governmental organizations and civil society institutions of the CIS countries, the promotion of network communications of cooperation in ensuring international humanitarian exchange are called priorities for the development and dissemination of positive sentiments in the post-Soviet space.

Keywords: world space, language, international activity, compatriots, cooperation, state, tension, education system, economics, science.

For citation: Konysheva Y.S. 2021. Mechanisms and tools of humanitarian and cultural cooperation between Russia and the states in the post-Soviet space. Via in tempore. History and political science. 48 (4): 942-952 (in Russian). DOI: 10.52575/2687-0967-2021-48-4-942-952.

Прежде всего необходимо акцентировать внимание на анализе литературы, используемой при написании данной статьи, с помощью которой автору удалось более подробно и результативно подойти к проблеме, представленной в статье. Для написания данной работы использовались актуальные статьи. Во внимание принимались статьи выдающихся экспертов-практиков в области изучения взаимодействия России с другими странами на постсоветском пространстве, в том числе эксперта МГИМО Е.Г. Пономаревой [Пономарева, 2013]. Для более углубленного изучения проблемы международных отношений я обратилась к статье ректора МГИМО А.В. Торкунова [Торкунов, 2013]. С целью более подробного представления о военно-техническом, экономическом и социальном развитии России автору необходимо было познакомиться со статьей К.П. Буртного [Буртный, 2020]. Проблему мягкой силы раскрыли в своих работах Дж. Най [Най, 2006], А.А. Громыко [Громыко, 2013], А.О. Наумов [Наумов, 2015], К.Р. Сарханянц [Сарханянц, 2020] и др.

Будущее Российской Федерации невозможно за пределами мирового пространства и вне всеобщей общемировой системы. Будущее любого государства и его населения целиком и полностью связано с историческими процессами, происходящими в этом государстве, с событиями и процессами в экономической сфере, на внутриполитической арене, со всей совокупностью социальных структур, с развитием в области культуры и искусства советского, а теперь и постсоветского, российского общества. Современная мировая система на протяжении веков претерпевала изменения и, не побоюсь этого слова, эволюционировала.

Российская Федерация имеет границы по суше и по морю с 18 государствами. При этом Российская Федерация граничит с 8 государствами, ранее входившими в СССР [Волков, 2001]. В настоящее время Россия ведет активную внешнеполитическую и международную экономическую и гуманитарную деятельность.

На протяжении последних нескольких лет основной целью международной деятельности Российской Федерации является раскрытие потенциала международного сотрудничества России для обеспечения национальной безопасности государства, социального и экономического развития государства на международной арене. На мировом пространстве продолжается формирование геополитических сил. Данные процессы сопровождаются борьбой за экономические и природные ресурсы. Проявляются межгосударственные противоречия в области политики, экономики, что связано с борьбой за сферы влияния. Все эти процессы и действия не способствуют нормализации спорных моментов, $\mathrm{a}$, напротив, увеличивают вероятность возникновения конфликтов как на государственном, так и региональном уровнях. Для того чтобы поддерживать и сохранять мир, государствам необходимо всегда находиться в состоянии диалога и постоянных контактов на разных уровнях и в разных сферах. Каким образом можно поддерживать связи между государствами? Конечно же, помогают в этом международные организации и институты, 
членами которых являются государства-партнеры. Основными организациями, благодаря которым государства на постсоветском пространстве имеют возможность поддерживать отношения, являются ЕАЭС, СНГ, ШОС.

Россия, как и прежде, выступает за развитие и активное продвижение курса на укрепление международного мира. Основными понятиями для достижения целей в мировом масштабе являются всеобщая безопасность и стабильность. Россия стремится выстраивать и формировать отношения добрососедства с сопредельными государствами. Наша страна содействует устранению имеющихся конфликтных моментов и ориентирует свою политическую и дипломатическую деятельность на снижение количества вновь образованных ситуаций. Целью деятельности является снятие напряженности в соседних приграничных государствах. Российская Федерация открыта к диалогу со всеми государствами и всегда призывает партнеров к честному диалогу и отказу от политики двойных стандартов. Это позволит запустить серьёзный прямой диалог между представителями государств и поспособствует продвижению принципов международного взаимодействия с целью решения острых проблем современного мира.

За последние годы при помощи активной политической деятельности Президента Российской Федерации и военно-политического руководства страны, а также благодаря проведению отличной дипломатической деятельности нашего государства отношение к России на мировой арене изменилось. Российская Федерация принимает участие в решении важнейших мировых проблем в разных аспектах и сферах. Российская Федерация принимает участие во многих событиях международного уровня. Россия является весомым участником многих международных организаций. Но, к сожалению, Россия продолжает подвергаться информационным нападкам и информационной агрессии [Буртный, 2020].

Несмотря на сложную обстановку, Российская Федерация всегда является важным участником на мировой арене. Она состоит в организациях различного рода деятельности и направленности. Российская Федерация неразрывно связана с другим миром, с мировыми экономиками, мировыми политическими процессами.

В мире постоянно происходят изменения, которые так или иначе заставляют государства считаться с ними. При принятии решений и анализе происходящего, с целью поднять и удержать авторитет государства и интерес к нашей стране и русскому языку, России приходится обращаться к мировому опыту. В данном случае речь идет о концепте «мягкой силы» (soft power) Джозефа Ная. Джозеф Най младший является значимой фигурой в политической жизни США. Руководитель Школы государственного управления им. Дж. Ф. Кеннеди, к тому же профессор Гарвардского университета и член американской Академии искусств и наук [Най, 2006].

Что же представляет собой понятие «мягкой силы»? Это способность государства или личности добиваться успеха или нужного результата при участии союзников, не применяя при этом принуждения либо силы. Это явная противоположность жесткой силы. По словам Дж. Ная, язык и культура представляют основу понятия и являются главным инструментом «мягкой силы». Эти два понятия и играют основную роль в формировании международных отношений и в выстраивании связей.

Концепция «мягкая сила» получила известность благодаря ее широкому использованию в политике: и, кстати, наработки Дж. Ная были приняты в США основополагающими при формировании международных связей и в политике [Най, 2006].

Президент нашей страны Владимир Путин на совещании послов и постоянных представителей России, имеющем место в 2021 году, призвал коллег и дипломатов обратить внимание на необходимое и полезное использование мягкой силы в своей деятельности. И это может поспособствовать активному применению интересов и подходов с помощью убеждения, привлекая внимание к своей стране и формированию положительного образа государства. По словам нашего президента, нужно брать 
за основу достижения в материальной, духовной, культурной и в интеллектуальной сферах.

В современном быстро развивающемся мире к инструментам «мягкой силы» можно отнести не только язык и культуру, но и СМИ, интернет, социальные сети. Основной замысел «мягкой силы» (иначе, soft power) ориентирован на формирование такой власти, которая способна привлекать внимание и формировать позитивное представление о ее действиях. А достигаться такой успех должен при помощи невидимого контроля поведения и реакции людей и благодаря информационной среде. Поэтому государственное управление не должно брать за основу только убеждение или же уговаривание людей. Государство имеет возможность и контролировать их реакцию на определенные события [Пономарева, 2013]. На повестке дня на совещании рассматривалась возможность реализации закона «О государственном языке Российской Федерации», а также поддержка и распространение русского языка и русской литературы за рубежом. Необходимо отметить, что на нашей стране лежит огромная ответственность за сохранение и распространение русского языка и литературы. К сожалению, в последнее время выявляются попытки искусственно сократить условные границы использования русского языка в мире. К сожалению, такая тенденция прослеживается и в странах на постсоветском пространстве.

Перед Россией поставлены две основные цели по сохранению значимости и важности русского языка в мире. Первая - обеспечение всеобщей мировой конкурентоспособности языка, для чего необходимо самому населению России быть грамотным. И вторая это поддержка русского языка и русскоязычного населения за рубежом.

Целью данных решений является сохранение суверенитета и целостности государства, защита прав населения как в нашей стране, так и за пределами страны.

В 2010 году Президентом России были определены и сформированы основные направления политики Российской Федерации в сфере международного культурногуманитарного сотрудничества. Данная Концепция была принята для того, чтобы реализовать основные направления политики России в этой области.

В 2015 году Президентом Российской Федерации была принята Концепция государственной поддержки русского языка за рубежом. В эту Концепцию вошли основные цели, взгляды и задачи, ориентированные на деятельность России в вопросах о поддержке русского языка за рубежом и в государствах на постсоветском пространстве. В этой концепции говорится о том, что целью международной деятельности Российской Федерации является расширение международного, культурного и гуманитарного сотрудничества. Важным аспектом в данной концепции выступает формирование положительного образа нашей страны как актора на мировой арене.

С момента распада СССР на постсоветском пространстве можно было отметить значимые события. Среди них были и положительные: создание Содружества Независимых Государств, Таможенного союза, ЕАЭС, сотрудничество стран постсоветского пространства в экономической, политической и гуманитарной сферах. Также были и отрицательные моменты. К ним относятся военные и политические конфликты. Стоит отметить, что отношения России с бывшими советскими республиками все еще продолжают выстраиваться. Остаются еще спорные моменты и конфликты разного рода со странами Балтии по поводу исторического наследия постсоветского периода.

Есть такая фраза Михаила Ломоносова: «Народ, не знающий своего прошлого, не имеет будущего». Данная фраза актуальна сейчас как никогда ранее. Для того чтобы молодежь в России и в странах на постсоветском пространстве помнила свою историю, необходимо как можно более активно развивать связи между государствами на постсоветском пространстве. Очевидно, что страны на постсоветском пространстве являются самостоятельными государствами, но у них была и есть общая история. Знание общей истории 
в данном случае - это и есть то прошлое, без которого мы не можем двигаться дальше и развиваться.

Нужно отметить, что в настоящее время связи между государствами действительно налаживаются и активизируются. И немаловажную роль в развитии отношений играют субъекты Российской Федерации. В данной статье мы сможем привести примеры удачного и результативного гуманитарного и культурного, технического и экономического сотрудничества.

В качестве примера хотелось бы описать деятельность Правительства Белгородской области на постсоветском пространстве. Как приграничная область, Белгородская область принимала активное участие в жизнеобеспечении людей, прибывающих из соседнего сопредельного государства - Украины. На территории Белгородской области продолжает действовать координационная группа по организации подготовки, встречи и размещения прибывающего населения из соседнего государства. В связи со сложившейся ситуацией, региональное управление по труду и занятости населения в свое время отвечало за организацию мероприятий по трудоустройству граждан, прибывших из Украины, в том числе людям, обратившимся за помощью в поиске работы в службы занятости населения.

Основная цель службы занятости, в свою очередь, заключалась и заключается в том, чтобы подобрать подходящие варианты трудоустройства для прибывающих из сопредельного государства граждан, учитывая при этом интересы местного населения. Согласно статистике, в 2016 году было трудоустроено около 100 человек ${ }^{209}$.

В июне 2016 года в рамках сотрудничества имел место форум, организованный по инициативе Института приграничного сотрудничества и интеграции Белгородского государственного национального исследовательского университета. На уровне муниципалитетов было подписано соглашение о побратимских связях между Веселолопанским сельским поселением Белгородского района и селом Русская Киселия, расположенном в Гагаузии в Республике Молдова.

В Белгородском государственном национальном исследовательском университете интенсивную работу по развитию сотрудничества ведет управление международного сотрудничества.

Главной задачей управления является формирование и контроль за обеспечением функций, ключевых направлений международной деятельности университета. С помощью этого учебная, научная и научно-методическая работа университета становится более эффективной.

Перед управлением международного сотрудничества НИУ «БелГУ» стоят следующие задачи:

- $\quad$ координация деятельности подразделений университета, отвечающих за международные программы и соглашения;

- $\quad$ контакты с международными организациями внутри нашей страны и за рубежом (взаимодействие с посольствами других государств и продвижение международных связей университета);

- прием и сопровождение в процессе обучения иностранных студентов в соответствии с государственными образовательными стандартами;

- прием иностранных делегаций и граждан;

- подготовка необходимой документации для выезда за рубеж в командировки сотрудников и студентов университета;

${ }^{209}$ Министерство иностранных дел Российской Федерации [официальный сайт]. Белгородская область. О международной и внешнеэкономической деятельности Белгородской области в первом полугодии 2016г. URL: http://www.mid.ru/ru/maps/ru/ru-bel//asset_publisher/Ez0NRjkfNHsl/content/id/2443709 (дата обращения: 07.10.2021). 
- паспортно-визовый контроль. Ревизия по соблюдению законодательства Российской Федерации и правил внутреннего распорядка университета иностранными гражданами, прибывшими в Россию в рамках сотрудничества;

- подготовка информационных и справочных материалов на тему международной деятельности университета ${ }^{210}$.

На уровне университета проводятся международные тематические конференции, семинары, форумы по актуальным проблемам сотрудничества в образовательной сфере. Также осуществляется студенческий обмен.

Администрация Владимирской области также интенсивно развивает свои международные отношения и международные связи с иностранными государствами. В 2015 году был сформирован план мероприятий, ориентированный на развитие торговоэкономического, научного и технического, а также культурного сотрудничества между Владимирской областью и Республикой Беларусь. Изначально план мероприятий был рассчитан на 2015 и 2016 годы, с учетом всех предложений Правительства Республики Беларусь, которые включали в себя 29 актуальных мероприятий, ориентированных на расширение двустороннего сотрудничества ${ }^{211}$.

На сегодняшний день Владимирская область развивает отношения с Республикой Беларусь более интенсивно. В 2020 году во Владимире проходил международный бизнесфорум, участие в котором приняли представители Республики Беларусь. Между Республикой Беларусь и Владимирской областью налажены не только дружественные, но и деловые взаимовыгодные связи. И на сегодняшний день они становятся только прочнее и результативнее.

Владимирскую область за последние годы посетили как иностранные делегации, так и делегации субъектов Российской Федерации. Целью данных визитов является обсуждение всевозможных направлений сотрудничества. Для достижения целей проводятся переговоры с руководством региона.

Администрация Владимирской области, в свою очередь, организовала визиты своих представителей в Республику Беларусь. Результатом плодотворной работы являются соглашения о сотрудничестве в торгово-экономической, научно-технической и социальнокультурной сферах между администрацией Владимирской области и представителями Республики Беларусь.

Владимирская область всегда была интересна как для российских, так и для иностранных туристов. И это не случайно - Владимирская область является колыбелью российской государственности, культуры и истории, ведь именно из ВладимироСуздальского княжества выделилось Московское княжество, после чего смогло объединить раздробленные русские земли.

Калужская область также активно участвует в развитии международных и межрегиональных связях с государствами на постсоветском пространстве. Данный субъект тесно сотрудничает с Республикой Беларусь в экономическом, техническом и научном направлениях. В данной статье представлены только некоторые регионы России, которые активно развивают международные связи: Калужская, Владимирская, Белгородская области.

Можно констатировать, что культурное и гуманитарное сотрудничество как одно из важнейших направлений внешней политики России является своеобразным

\footnotetext{
210 Белгородский государственный национальный исследовательский университет [Официальный сайт]. Управление международного сотрудничества. http://www.bsu.edu.ru/bsu/structure/detail.php?ID=10518 (дата обращения: 05.10.2021).

211 Администрация Владимирской области [Официальный сайт]. Департамент инвестиций и внешнеэкономической деятельности. Международное сотрудничество. URL: /http://dvs.avo.ru/mezdunarodnoe-sotrudnicestvo; URL:https://army.ric.mil.ru/Stati/item/278337/> (дата обращения: 07.10.2021).
} 
проводником для развития внешнеэкономических, политических связей между государствами в постсоветский период. На мировой политической арене происходят события, которые иногда формируют в умах людей негативный образ России и настраивают многие бывшие союзные страны против нашего государства. В связи с этим важным аспектом является предоставление и распространение достоверной и полной информации о России. В данном случае СМИ играет самую главную роль не только в области культурного взаимодействия, но и в других аспектах сотрудничества между странами.

Когда речь идет о выстраивании связей и добрососедских отношений с государствами на постсоветском пространстве, необходимо сказать, прежде всего, о Россотрудничестве. Это Федеральное агентство по делам соотечественников, проживающих за рубежом, и международному гуманитарному сотрудничеству. Основополагающей целью данной организации является расширение круга государств, дружественных по отношению к Российской Федерации. И нужно заметить, что с каждым годом добавляются новые инструменты для реализации задач на уровне организации. Сейчас выделяются два основных приоритета развития: 1) работа с молодежью; 2) расширение присутствия организации на постсоветском пространстве.

Учитывая современные реалии, Россотрудничество «идет в ногу со временем». Организуются интернет-фестивали, конкурсы и другие мероприятия. В качестве примера хотелось бы привести организацию подготовки к празднованию 75 -летия Победы в Великой Отечественной войне, которое отмечалось в 2020 году. Велась активная работа по привлечению партнерских организаций из стран на постсоветском пространстве и экспертов.

Главной деятельностью Россотрудничества является активная работа с общественными организациями и экспертным сообществом. Российские эксперты вовлечены в данную работу для внесения корректив и реализации проектов. Целью деятельности экспертов является продвижение и распространение русского языка и российского образования за рубежом и в странах постсоветского пространства ${ }^{212}$. Портал под названием «Системная поддержка русских школ», созданный Россотрудничеством, активно функционирует. Это информационный портал, который предоставляет образовательным организациям бесплатный доступ к 180 тысячам электронных книг.

Со стороны нашего государства предпринято много мер по стабилизации отношений культурного и гуманитарного сотрудничества на постсоветском пространстве, но еще есть аспекты, которые требуют доработки и совершенствования. Необходимость диалога со странами бывшего СССР является очевидным, скорее даже фундаментальным аспектом во внешнеполитической деятельности России. Необходимо учитывать и то, что на современном этапе развития стран под влиянием глобализации происходят сложные процессы. Формируется новая система международных отношений. На первое место, кроме факторов влияния государства на мировую политику и военно-политического и экономического ресурсов, выходят факторы «мягкой силы» [Наумов, 2015].

Проблематика статьи состоит в том, чтобы выявить основные аспекты развития международных отношений России и обозначить перспективы развития связей с государствами на постсоветском пространстве. Согласно мнению специалистов, за счет реализации стратегии экспорта образовательных услуг у российской системы образования возрастет способность конкурировать с другими аналогичными системами в

212 Глава Россотрудничества назвала главной миссией расширение круга друзей Российской Федерации. 2019. Федеральное агентство новостей. Лента новостей [Электронный pecypc]. URL: https://riafan.ru/1168796-glava-rossotrudnichestva-nazvala-glavnoi-missiei-rasshirenie-kruga-druzei-rf (дата обращения: 10.07.2021). 
других государствах. Нужно отметить, что у России есть положительный опыт в области создания сетевого университета стран СНГ в формате магистратуры по аналогии с «Эразмус-Мундус» [Сенашенко, 2013]. Иначе говоря, разрабатывалась программа, которая функционирует в пределах единого образовательного пространства государствчленов СНГ [Торкунов, 2013]. Проект датирован 2008 годом по инициативе университета РУДН. В состав Сетевого университета вошли 16 ведущих вузов из 8 стран: Армении, Беларуси, Казахстана, Кыргызстана, Молдовы, России, Таджикистана и Украины. Этот образовательный проект создан с целью развития сотрудничества между вузами в пределах территории стран СНГ [Слепухин, Костюченко, 2011]. В первую очередь студенты получают базовое, то есть основное образование в университете своего государства (в Киргизии, Казахстане или Республике Беларусь), а после этого студенты из стран СНГ смогут продолжить обучение в магистратуре в России. Они могут обучаться в таких высших учебных заведениях, как РУДН, МГУ, МГИМО и в других университетах в Российской Федерации [Рудаков, Полянин, Марченкова, 2015].

Хотелось бы отметить, что российские вузы только начинают воплощать в жизнь подобные образовательные проекты, есть еще недоработки в применении на практике учебных программ на иностранных языках. Еще нет большого количества международных согласованных между вузами научных исследований по различным направлениям для того, чтобы сделать эти учебные программы обучения международными. Но важно сказать, что активная работа в этом направлении ведется. Нашему государству еще есть над чем поработать, но нужно отметить, что начало уже положено и ведется активная работа с целью развития нашей системы образования, формирования ее привлекательности на постсоветском пространстве.

В современных реалиях распространение за рубежом языка и литературы того или иного государства определяют уровень признания государства на мировой арене и его влияния. Исходя из этого, русский язык для России является основой для продвижения экономических и гуманитарных интересов нашей страны. Формируется положительный образ нашей страны и граждан, и, как следствие, формируется соответственное отношения к Российской Федерации со стороны мирового сообщества. Все эти процессы целиком и полностью зависят от уровня распространения и использования русского языка за рубежом. По прогнозам экспертов, результатом деятельности России по продвижению русского языка станет укрепление авторитета нашей страны и более активное присутствие России во всех аспектах международной деятельности.

Для того чтобы правильно и грамотно осуществлять деятельность по поддержке русского языка, важно учитывать и оценивать исторические особенности развития языка: чем является русский язык, какую роль он играет как в нашей стране, так и за рубежом. Русский язык - это фундамент нашей истории и культуры. Русский - это наш государственный язык. Этим языком при общении пользуется русскоязычное население в государствах на постсоветском пространстве. Важно помнить, что данный язык используют при общении наши соотечественники за рубежом, обозначая тем самым свою культурную и языковую принадлежность [Громыко, 2013]. Русский язык является официальным или же рабочим языком таких международных организаций: ООН, ЮНЕСКО, ОДКБ, ШОС, ОБСЕ, МАГАТЭ, ВОЗ, ЕАЭС и других ${ }^{213}$. А также остается вторым государственным языком в некоторых странах на постсоветском пространстве (например, в Казахстане).

213 Указ Президента Российской Федерации от 03.11.2015. Концепция государственной поддержки и продвижения русского языка за рубежом». URL: www.kremlin.ru/acts/news/50644. (дата обращения: 04.07.2021). 
В заключение нужно сказать, что, к сожалению, меры, предпринятые нашим государством, не могут пока переломить настроения так называемой «русофобии» как в странах бывшего СССР, так и в мире в целом. Это явление уходит корнями к концу XVIII - началу XIX веков. Русофобия как феномен выражена неприязнью ко всему русскому, в том числе и к языку. В последние годы Российская Федерация успешно воплощает в жизнь меры по поддержке и продвижению русского языка в мире. Россия оказывает всю необходимую помощь и поддержку соотечественникам, проживающим в других государствах. В наше время существует необходимость сохранения для русских людей за рубежом доступа к русской литературе и культуре. Применение на практике мер по продвижению языка имеет свои плоды. Интерес к изучению русского языка возрастает. Расширение международного, политического, экономического, научного, образовательного, культурного и гуманитарного сотрудничества Российской Федерации с государствами на постсоветском пространстве на уровне международных гуманитарных организаций способствует положительной динамике в данном аспекте.

\section{Список литературы}

1. Асадов Б.Р., Баранов А.С., 2016. Организованная молодежная среда России в контексте международного гуманитарного взаимодействия на постсоветском пространстве. Управленческое консультирование, 9: 172-182.

2. Буртный К.П. 2020. Россия в современном мире. Основные направления социальноэкономического, политического и военно-технического развития страны. Задачи офицерского состава на 2021 учебный год. Армейский сборник, 11; 109-115. URL: https://army.ric.mil.ru/Stati/item/278337/> (дата обращения: 07.10.2021).

3. Волков В.А. 2001. Вместе или порознь? Славянские народы на пороге XXI в.: диагноз и прогнозы. Родина. 1-2: 150-156. URL:https://archive.vn /20130103170809/www.istrodina.com/rodina_articul.php3.

4. Громыко А.А. 2013. Русский язык и культура в политике «мягкой силы» России. Большая Европа в глобальном мире: новые вызовы - новые решения. М., Ин-т Европы РАН, 143.

5. Най Дж. 2006 «Мягкая сила» и американо-европейские отношения. Прогнозис, 8. URL:intelros.ru/2007/08/09/mjagkaja_sila_i_evropejjskoamerikanskie_otnoshenija.html (дата обращения: 10.10.2021.)

6. Наумов А.О. 2015. «Мягкая сила» и внешнеполитический имидж Российской Федерации. Истина. URL: https://istina.msu.ru/publications/article/9147444/ URL:https://army.ric.mil.ru/Stati/item/278337/> (дата обращения: 07.10.2021).

7. Никонов В.А. 2015. Россия: вызовы и возможности. Стратегия России. 1: 25-27.

8. Пономарева Е.Г. 2013. Железная хватка «мягкой силы». МГИМО (ФГАОУ ВО «Московский государственный университет международных отношений (университет) Министерства иностранных дел Российской Федерации) [Официальный сайт]. Эксперты МГИМО. URL: https://mgimo.ru/about/news/experts/238257/ (дата обращения: 10.10.2021).

9. Рудаков О.В., Полянин А.В., Марченкова Л.М., 2015. Россия на рынке международного образования: мировые рейтинги. Среднерусский вестник общественных наук, 6 : 285-293.

10. Сарханянц К.Р. 2020. Владимир Путин обеспечил Россию мягкой силой. Коммерсантъ. URL: https://www.kommersant.ru/doc/4267683/(дата обращения: 05.10.2021).

11. Сенашенко В.С. 2013. Образование и процессы глобализации. Высшее образование в России. 1: 48-53.

12. Слепухин А.Ю., Костюченко Л.С. 2011. Трансформация образовательной политики в Европе на современном этапе. Власть, 10: 151-154.

13. Токмакова М.В. 2013. Интеграционные процессы на постсоветском пространстве. Вестник Московского университета. Серия 18. Социология и политология. 189-194. 
14. Торкунов А.В. 2013. Образование как инструмент «мягкой силы» во внешней политике России». URL: http/ticrussiancouncil.ru/analys-and-comments/analytics/obrazovanie-kakinstrument-myagkoy-sily-vo-vneshney-politike (дата обращения 15.08.2021)

\section{References}

1. Asadov B.R., Baranov A.S., 2016. Organizovannaya molodezhnaya sreda Rossii v kontekste mezhdunarodnogo gumanitarnogo vzaimodejstviya na postsovetskom prostranstve [Organized youth environment in Russia in the context of international humanitarian interaction in the post-Soviet space]. Upravlencheskoe konsul'tirovanie, 9: 172-182.

2. Burtnyj K.P. 2020. Rossiya v sovremennom mire. Osnovnye napravleniya social'noekonomicheskogo, politicheskogo i voenno-tekhnicheskogo razvitiya strany. Zadachi oficerskogo sostava na 2021 uchebnyj god [Russia in the modern world. The main directions of the socio-economic, political and military-technical development of the country. Officers' Tasks for the 2021 Academic Year]. Armejskij sbornik, 11; 109-115. URL:https://army.ric.mil.ru/Stati/item/278337/> (data obrashcheniya: 07.10.2021).

3. Volkov V.A. 2001. Vmeste ili porozn'? Slavyanskie narody na poroge XXI v.: diagnoz i prognozy [Together or apart? Slavic peoples on the threshold of the XXI century: diagnosis and $\begin{array}{llll}\text { predictions]. } & \text { Rodina. } & 1-2: & \text { URL:https://archive.vn }\end{array}$ /20130103170809/www.istrodina.com/rodina_articul.php3.

4. Gromyko A.A. 2013. Russkij yazyk i kul'tura v politike «myagkoj sily» Rossii. Bol'shaya Evropa v global'nom mire: novye vyzovy - novye resheniya [Russian language and culture in the policy of «soft power» in Russia. Greater Europe in a Global World: New Challenges - New Solutions]. M., In-t Evropy RAN, 143.

5. Naj Dzh. 2006 «Myagkaya sila» i amerikano-evropejskie otnosheniya [Soft Power and USEuropean Relations]. Prognozis, 8. URL:intelros.ru/2007/08/09/mjagkaja_sila_i_evropejjskoamerikanskie_otnoshenija.html (data obrashcheniya: 10.10 .2021$)$.

6. Naumov A.O. 2015. «Myagkaya sila» i vneshnepoliticheskij imidzh Rossijskoj Federacii. [«Soft power» and the foreign policy image of the Russian Federation]. Istina. URL: https://istina.msu.ru/publications/article/9147444/ URL:https://army.ric.mil.ru/Stati/item/278337/> (data obrashcheniya: 07.10.2021).

7. Nikonov V.A. 2015. Rossiya: vyzovy i vozmozhnosti [Russia: challenges and opportunities]. Strategiya Rossii. 1: 25-27.

8. Ponomareva E.G. 2013. Zheleznaya hvatka «myagkoj sily» [The iron grip of «soft power»]. MGIMO (FGAOU VO «Moskovskij gosudarstvennyj universitet mezhdunarodnyh otnoshenij (universitet) Ministerstva inostrannyh del Rossijskoj Federacii) [Oficial'nyj sajt]. Eksperty MGIMO. URL: https://mgimo.ru/about/news/experts/238257/ (data obrashcheniya: 10.10.2021).

9. Rudakov O.V., Polyanin A.V., Marchenkova L.M., 2015. Rossiya na rynke mezhdunarodnogo obrazovaniya: mirovye rejtingi [Russia in the international education market: world rankings]. Srednerusskij vestnik obshchestvennyh nauk, 6: 285-293.

10. Sarhanyanc K.R. 2020. Vladimir Putin obespechil Rossiyu myagkoj siloj [Vladimir Putin gave Russia soft power]. Kommersant". URL: https://www.kommersant.ru/doc/4267683/(data obrashcheniya: 05.10.2021).

11. Senashenko V.S. 2013. Obrazovanie i processy globalizacii [Education and processes of globalization]. Vysshee obrazovanie v Rossii. 1: 48-53.

12. Slepuhin A.Yu., Kostyuchenko L.S. 2011. Transformaciya obrazovatel'noj politiki v Evrope na sovremennom etape [Transformation of educational policy in Europe at the present stage]. Vlast', 10: $151-154$.

13. Tokmakova M.V. 2013. Integracionnye processy na postsovetskom prostranstve [Integration processes in the post-Soviet space]. Vestnik Moskovskogo universiteta. Seriya 18. Sociologiya i politologiya. 189-194.

14. Torkunov A.V. 2013. Obrazovanie kak instrument «myagkoj sily» vo vneshnej politike Rossii» [Education as an instrument of «soft power» in Russian foreign policy»]. URL: http/ticrussiancouncil.ru/analys-and-comments/analytics/obrazovanie-kak-instrument-myagkoy-sily-vovneshney-politike (data obrashcheniya 15.08.2021). 
Конфликт интересов: о потенциальном конфликте интересов не сообщалось.

Conflict of interest: no potential conflict of interest related to this article was reported.

ИНФОРМАЦИЯ ОБ АВТОРЕ

Конышева Юлия Сергеевна, аспирант, Среднерусский институт управления - филиал РАНХиГС, г. Орел, Россия

\section{INFORMATION ABOUT THE AUTHOR}

Yulia S. Konysheva, postgraduate student Central Russian Institute of Management - branch of RANEPA, Orel, Russia 